\title{
Effect of incubation system on the development of intestinal villi, metabolism, and performance of one- to forty-day-old broiler chickens
}

\author{
Araceli Pacheco Villanueva1, Patrícia Diniz Ebling1', Gabriel Colombo Pontalti' ${ }^{1}$, Andréa \\ Machado Leal Ribeiro ${ }^{1}$
}

${ }^{1}$ Universidade Federal do Rio Grande do Sul, Departamento de Zootecnia, Porto Alegre, RS, Brazil.

ABSTRACT - An experiment was performed to evaluate the effect of the incubation system - multiple-stage (MS) and single-stage (SS) - on the characteristics at hatching, intestinal morphology, metabolism, and performance of Cobb-500 chickens from 1 to $40 \mathrm{~d}$ of age. A total of 1,968 fertile eggs were incubated in two setters under commercial conditions. Birds hatched in SS were longer than those hatched in MS, and the females had higher relative intestinal weight compared with males. However, at hatching, there were no differences in BW and yolk-free body mass from incubation system or sex. In the period from 1-40 d, the birds hatched in SS were heavier, had higher weight gain and better adjusted feed conversion, without differences in feed intake and feed conversion. This result is due mainly to MS females, which always, although in some periods only numerically, exhibited worse responses than the other treatment, lowering the average MS bird performance. Sex influenced the duodenal villi height in chickens at $0 \mathrm{~d}$; females showed larger villi than males. Moreover, the birds hatched in SS had deeper crypts than those hatched in MS. At $7 \mathrm{~d}$, because males had higher feed intake, the differences in duodenal villi height found at hatching disappeared, leaving only a gender effect on jejunum crypt depth: females showed deeper crypts. As regards the metabolism coefficients of nutrients from 5 to $7 \mathrm{~d}$, females were more efficient in metabolizing energy and showed higher apparent metabolizable energy corrected for nitrogen values than males, with no differences caused by the incubation system. The best incubation conditions are obtained with the single-stage system, based on the improved broiler performance $(2.98 \%)$, especially in the females $(5.04 \%)$.

Key Words: hatching, intestinal morphology, multi-stage, single-stage

\section{Introduction}

The increased weight of broiler chickens over the last 25 years was not due to any change in the incubation time of the eggs. Currently, the incubation time represents between $30 \%$ and $40 \%$ of the total broiler life, whereas 25 years ago, it represented $20 \%$ to $25 \%$ (Hulet, 2007). Thus, the impact of the incubation conditions on embryonic growth is more critical for the success of birds and health in their subsequent performance. Under commercial conditions, one of the most common stresses that embryos encounter inside the setter occurs if conditions such as temperature, humidity and ventilation are not adequate (Bruzual et al., 2000; Peebles et al., 2001; De Smit et al., 2006; Leksrisompong et al., 2007).

At present, there are multi-stage (MS) and single-stage (SS) incubation systems. The MS system contains embryos

Received January 29, 2016 and accepted May 24, 2016.

Corresponding author: aribeiro@ufrgs.br

http://dx.doi.org/10.1590/S1806-92902016000900004

Copyright (C) 2016 Sociedade Brasileira de Zootecnia. This is an Open Access article distributed under the terms of the Creative Commons Attribution License (http://creativecommons.org/licenses/by/4.0/), which permits unrestricted use, distribution, and reproduction in any medium, provided the original work is properly cited. at different stages of development and is operated with average parameters of temperature, humidity, and ventilation, which partially satisfy the embryonic requirements. The SS system employs profiles that change according to the incubation time, providing, in theory, the necessary conditions for embryos.

It has been observed that most multi-stage incubation systems do not provide enough heat to embryos in their early development (Oviedo-Rondón et al., 2009a). Likewise, the increased growth rate of embryos leads to an increase in the metabolic heat production of the eggs, and it accumulates inside the setter (Barri et al., 2011). Therefore, although setters have been programmed to operate at temperatures of $37.4{ }^{\circ} \mathrm{C}$, if there is not adequate ventilation to remove the excess heat generated by embryos, those machines may reach temperatures up to 41.1 to $41.7^{\circ} \mathrm{C}$, particularly in the second half of the incubation (Hulet, 2007). Overheating during this time affects embryonic development, decreasing the yolk-free mass of hatchlings (Lourens et al., 2005; Willemsen et al., 2010) and their subsequent performance (Hulet et al., 2007; Oviedo-Rondón et al., 2009b; Molenaar et al., 2010b).

During the time that embryos are within the hatcher, organ development occurs. The last four days of incubation 
are a decisive point, and any stress in this phase can produce changes in the growth rate of digestive organs (Uni et al., 2003), such as high eggshell temperatures $\left(40.3{ }^{\circ} \mathrm{C}\right)$ (Leksrisompong et al., 2007) or $\mathrm{O}_{2}$ concentrations lower than $21 \%$ (Wineland et al., 2006).

The objective of the present study was to determine the differences in one-day-old chicks, in metabolism coefficients during the first seven days posthatch, in performance and in intestine morphological characteristics from multi-stage and single-stage incubation systems.

\section{Material and Methods}

All procedures described were approved by the Ethics Committee in Animal Use of Universidade Federal do Rio Grande do Sul, located in Rio Grande do Sul, Brazil.

We performed three experiments in the hatchery, experimental farm, and metabolism room to evaluate the incubation process and hatchlings, broiler performance, and chicken metabolism.

A total of 1,968 fertile eggs stored for three days, weighing between 65 and $68 \mathrm{~g}$, from a 44-wk-old Cobb500 broiler breeder flock, were used. In a commercial hatchery, 1,200 eggs were incubated in a SS setter (Airstreamer A12S model, Petersime NV, Zulte, Belgium) distributed into eight trays of 150 eggs each, and 768 eggs were incubated in a MS setter (MG125 model, Casp, São Paulo, Brazil) distributed into eight trays of 96 eggs each. Each tray was considered an experimental unit, and all trays were distributed in a completely randomized design. The setter capacities were 57,600 and 126,000 eggs for SS and MS, respectively. The incubation profiles used in this experiment were those commonly used for broiler chickens in the industry (Table 1). The transfer time from the setter to the hatcher and the total incubation time were 456 and $504 \mathrm{~h}$, respectively, for both systems.
At hatching, five chicks of each sex were randomly selected per experimental unit. The evaluations were as follows: the selected animals were weighed individually and then killed by cervical dislocation. The yolk was carefully separated and weighed to determine yolk-free body mass. The chicks were measured with a ruler from the beak tip to middle finger tip of the right leg.

Similarly, two chicks of each sex were randomly selected from each experimental unit for morphological intestine evaluation: the animals were weighed alive and then killed by cervical dislocation to weigh the intestine (small intestine, pancreas, and cecum). The relative intestine weight (RIW) was calculated using the following formula:

$$
\operatorname{RIW}(\%)=\frac{\text { intestine weight }}{\text { body weight }} \times 100
$$

Five centimeters of the duodenum (middle section of the pancreatic loop) and $6 \mathrm{~cm}$ of jejunum (midpoint between the end of the duodenal loop and Meckel's diverticulum) were taken from each sampled bird to evaluate the villus height $(\mathrm{VH})$ and crypt depth (CD). The collected intestines were gently flushed with $10 \%$ buffered formalin and stored in Falcon tubes containing the same solution until further analysis. The composition of $1 \mathrm{~L}$ of solution was $100 \mathrm{~mL}$ of $40 \%$ formaldehyde, $4 \mathrm{~g}$ of monobasic sodium phosphate, $6.5 \mathrm{~g}$ of dibasic sodium phosphate, and $900 \mathrm{~mL}$ of distilled water.

For the preparation of histological slides, the samples were dehydrated in an ascending series of alcohol $\left(70^{\circ}\right.$, $80^{\circ}, 95^{\circ}$, and $99^{\circ}$ ) with a total of six baths. Then, they were placed in xylol solution (three times), immersed in paraffin, and embedded in paraffin to form blocks. Subsequently, they were microtomized in $3 \mu \mathrm{m}$ sections, and three sections from each segment were placed on one slide and stained with hematoxylin-eosin (Luna, 1968).

All measurements of intestinal segments were made using images obtained by optical microscopy (Nikon).

Table 1 - Incubation profiles in multi-stage and single-stage systems

\begin{tabular}{|c|c|c|c|c|c|c|}
\hline \multirow{2}{*}{ Item } & \multicolumn{2}{|c|}{ Multi-stage } & \multicolumn{4}{|c|}{ Single-stage } \\
\hline & MT & WBT & $\mathrm{AT}_{\min }$ & $\mathrm{AT}_{\max }$ & EST & WBT \\
\hline \multicolumn{7}{|l|}{ In setter } \\
\hline Initial temperature, ${ }^{\circ} \mathrm{F}$ & 99.4 & 82.0 & 99.7 & 99.7 & 100.2 & 96.0 \\
\hline Final temperature, ${ }^{\circ} \mathrm{F}$ & 99.4 & 82.0 & 96.8 & 98.3 & 100.2 & 80.0 \\
\hline $\mathrm{N}$ of steps & \multicolumn{2}{|c|}{1} & \multicolumn{4}{|c|}{14} \\
\hline \multicolumn{7}{|l|}{ In hatcher } \\
\hline Final temperature, ${ }^{\circ} \mathrm{F}$ & 98.5 & 85.0 & 99.2 & - & - & 82.0 \\
\hline $\mathrm{N}$ of steps & \multicolumn{2}{|c|}{3} & \multicolumn{4}{|c|}{5} \\
\hline
\end{tabular}

MT - incubator air temperature; WBT - wet bulb temperature; $\mathrm{AT}_{\min }$ - minimum incubator air temperature; $\mathrm{AT}_{\max }$ - maximum incubator air temperature; EST - eggshel temperature. 
The images were captured with a camera attached to the microscope (Sony Super Steady Shot 9.1 megapixels) and transferred to an image analyzer (Image-Pro Plus, version 4.5.0.29, 2001). Villus height and CD were determined from villi in the first development stage (V1). Ten readings of $\mathrm{VH}$ and $\mathrm{CD}$ were performed per slide. One slide was prepared for each of the four birds selected from each experimental unit. The VH was measured from the apical to the basal region (crypt upper portion). The $\mathrm{CD}$ was measured from the base to the transition region between the crypt and villi.

Three hundred and thirty-six chicks from the hatchings described above (168 males and 168 females, 1-d-old) were randomly allocated to 28 floor pens (experimental unit, $1 \mathrm{~m} \times 1 \mathrm{~m}$ ) with nipple drinkers and feeders in a temperature-controlled room under a continuous light system. In the hatchery, the birds were vaccinated against Marek's disease. The transfer time of birds from the hatchery to the experimental unit was $13 \mathrm{~h}$, during which time the birds were kept without access to food and water. The chicks were distributed into four experimental groups with seven replicates of 12 birds each in a completely randomized design with a $2 \times 2$ factorial arrangement, with sex and incubation system (MS and SS) as the factors.

The diets were corn-soybean meal-based and were formulated to exceed NRC recommendations (NRC, 1994) (Table 2). The dietary phases were pre-starter (1 to $7 \mathrm{~d}$ ), starter ( 8 to $21 \mathrm{~d}$ ), grower ( 22 to $35 \mathrm{~d}$ ), and finisher (36 to $40 \mathrm{~d}$ ). All birds were provided with feed in mash form and water ad libitum throughout the grow-out period.

During the experimental period (1 to $40 \mathrm{~d}$ ), body weight $(\mathrm{BW})$, weight gain $(\mathrm{WG})$, feed intake $(\mathrm{FI})$, and feed conversion ratio $(\mathrm{FCR})$ were determined weekly. For the whole period, the adjusted feed conversion ratio (AFCR) for a weight of $3 \mathrm{~kg}$ was calculated. Dead birds were weighed and removed from the pens daily, and the data were used to correct the FCR. At $7 \mathrm{~d}$ of age, one bird per replicate with a weight close to the average weight of the pen was sacrificed by cervical dislocation to determine the RIW, $\mathrm{VH}$, and $\mathrm{CD}$ of duodenum and jejunum. The selected birds were fasted for $3 \mathrm{~h}$ and then were killed. The procedure for the collection of intestinal sections was as described in the previous section.

A total of 250 chicks from the hatching described above (130 males and 120 females, 1-d-old) were randomly allocated in 25 cages with wire floors (experimental unit, $0.95 \times 0.87 \times 0.27 \mathrm{~cm})$ in a temperature-controlled room with constant illumination. The evaluated treatments consisted of groups of birds from each sex and two incubation systems (MS and SS). The treatment groups had
6 replicates of 10 birds each, except for the males from MS system treatment, which consisted of seven replicates of the same number of animals. The experimental design was completely randomized with a $2 \times 2$ factorial arrangement, with sex and incubation system (MS and SS) as the factors. A pre-starter diet (Table 2) was used throughout the growout period ( 1 to $7 \mathrm{~d}$ ). Feed in mash form and water were provided ad libitum. The total collection method was used to determine metabolism. An initial adaptation period of four days was observed for the birds to adapt to the diet and environment, after which period total excreta collection was performed for three days (Cortés et al., 2009). The excreta were collected in plastic bags twice each day $(09.00$ and $16.00 \mathrm{~h}$ ) to prevent fermentation and stored at $-10{ }^{\circ} \mathrm{C}$ until further analysis. The dry matter (DM), nitrogen $(\mathrm{N})$ and gross energy (GE) in diets and excreta were determined in agreement with the AOAC (1996) to determine the coefficients of metabolization of dry matter, crude protein, gross energy, and apparent metabolizable energy corrected

Table 2 - Ingredient and nutrient composition of the experimental diets (as-is basis)

\begin{tabular}{|c|c|c|c|c|}
\hline Ingredient & $\begin{array}{l}\text { Pre-starter } \\
\left(\mathrm{g} \mathrm{kg}^{-1}\right)\end{array}$ & $\begin{array}{l}\text { Starter } \\
\left(\mathrm{g} \mathrm{kg}^{-1}\right)\end{array}$ & $\begin{array}{l}\text { Grower } \\
\left(\mathrm{g} \mathrm{kg}^{-1}\right) \\
\end{array}$ & $\begin{array}{c}\text { Finisher } \\
\left(\mathrm{g} \mathrm{kg}^{-1}\right)\end{array}$ \\
\hline Corn & 565.3 & 578.5 & 608.2 & 620.8 \\
\hline Soybean meal $47 \%$ & 367.2 & 347.6 & 315.9 & 304.5 \\
\hline Limestone & 13.7 & 12.1 & 11.3 & 11.5 \\
\hline Dicalcium phosphate & 10.1 & 8.6 & 9.4 & 7.8 \\
\hline Soybean oil & 29.8 & 42.2 & 43.4 & 45.9 \\
\hline Salt & 5.1 & 4.5 & 4.6 & 4.3 \\
\hline Vitamin premix $^{1}$ & 0.4 & 0.4 & 0.4 & 0.4 \\
\hline Mineral premix ${ }^{2}$ & 0.7 & 0.7 & 0.7 & 0.7 \\
\hline DL-methionine & 3.7 & 3.1 & 3.1 & 2.4 \\
\hline L-lysine & 1.9 & 0.7 & 1.2 & 0.6 \\
\hline L-threonine & 1.7 & 1.2 & 1.4 & 0.7 \\
\hline Monensin $40 \%$ & 0.3 & 0.3 & 0.3 & 0.3 \\
\hline Ronozyme NP & 0.1 & 0.1 & 0.1 & 0.1 \\
\hline \multicolumn{5}{|l|}{ Nutrient profile } \\
\hline AME (kcal/kg) & 3,000 & 3,100 & 3,104 & 3,170 \\
\hline Crude protein $(\%)$ & 22.00 & 21.00 & 19.80 & 19.20 \\
\hline Digestible lysine (\%) & 1.32 & 1.18 & 1.13 & 1.05 \\
\hline Digestible met + cys $(\%)$ & 0.93 & 0.86 & 0.83 & 0.75 \\
\hline Digestible threonine (\%) & 0.86 & 0.78 & 0.76 & 0.67 \\
\hline Digestible tryptophan (\%) & 0.25 & 0.24 & 0.22 & 0.22 \\
\hline Calcium (\%) & 1.00 & 0.90 & 0.88 & 0.85 \\
\hline Total P (\%) & 0.57 & 0.53 & 0.53 & 0.50 \\
\hline Available P (\%) & 0.45 & 0.42 & 0.42 & 0.40 \\
\hline Sodium (\%) & 0.22 & 0.20 & 0.20 & 0.19 \\
\hline Chloride (\%) & 0.38 & 0.33 & 0.34 & 0.31 \\
\hline Potassium (\%) & 0.91 & 0.88 & 0.82 & 0.80 \\
\hline
\end{tabular}

AME - apparent metabolizable energy.

${ }^{1}$ Supplied per kilogram of feed: vitamin A - 9,280 IU from retinyl acetate; vitamin D - 2,240 IU from cholecalciferol; vitamin E - 20.8 IU from DL- $\alpha$-tocopheryl acetate; vitamin $\mathrm{K}-2.4 \mathrm{mg}$ from menadione bisulfite; thiamin - $2.4 \mathrm{mg}$ from thiamine mononitrate; riboflavin - $7.2 \mathrm{mg}$; pyridoxine - $3.6 \mathrm{mg}$ from pyridoxine hydrochloride; cobalamin - $0.016 \mathrm{mg}$ from cyanocobalamin; pantothenic acid $17.6 \mathrm{mg}$ from D-pantothenic acid; niacin - $52.8 \mathrm{mg}$ from nicotinic acid; folic acid $-0.96 \mathrm{mg}$; biotin - $0.08 \mathrm{mg}$ from D-biotin.

${ }^{2}$ Supplied per kilogram of feed: $\mathrm{Mn}-105 \mathrm{mg}$ from $\mathrm{MnSO}_{4} ; \mathrm{Zn}-70 \mathrm{mg}$ from $\mathrm{ZnO}$ $\mathrm{Fe}-56 \mathrm{mg}$ from $\mathrm{FeSO}_{4} ; \mathrm{Cu}-10.5 \mathrm{mg}$ from $\mathrm{CuO}$; $-0.84 \mathrm{mg}$ from KI; Se - $0.3 \mathrm{mg}$ from $\mathrm{Na}_{2} \mathrm{SeO}_{3}$. 
for nitrogen (AMEn). For $\mathrm{N}$ analysis of excreta, $\mathrm{HCl}$ was added (prior to drying) to prevent nitrogen loss during the drying process (Ribeiro et al., 2001).

All data collected were processed using the statistical software package SAS (Statistical Analysis System, version 9.0). Analyses of variance were performed using the GLM procedure (General Linear Models). When the means of the GLM were significantly different, they were further compared by Tukey's test. Only data on the intestinal morphology of 0 -d-old chicks were logarithm-transformed due to the high coefficient of variation.

\section{Results and Discussion}

The chicks hatched in the SS system exhibited the highest CL (Table 3), with a length approximately $1.06 \%$ and $2.56 \%$ higher than the males and females of the MS system, respectively. These results indicate that the incubation system influenced the CL $(\mathrm{P}<0.001)$ but did not affect the other characteristics. The difference in favor of the SS system can be explained because this system works with a varying incubation profile, meeting the embryo requirements as the incubation time progresses, whereas the MS system operates with average parameters of temperature and humidity due to the presence of eggs at different incubation times. Oviedo-Rondón et al. (2008) reported that embryos are sensitive to incubation conditions at any age of development but especially during the last

Table 3 - Body weight, relative yolk-sac weight, yolk-free body mass, relative intestine weight, and chicken length at hatching

\begin{tabular}{lccccc}
\hline Treatment & $\begin{array}{c}\text { BW } \\
(\mathrm{g})\end{array}$ & $\begin{array}{c}\text { RYW } \\
(\mathrm{g} / 100 \mathrm{~g})\end{array}$ & $\begin{array}{c}\text { YFBM } \\
(\mathrm{g})\end{array}$ & $\begin{array}{c}\text { RIW } \\
(\mathrm{g} / 100 \mathrm{~g})\end{array}$ & $\begin{array}{c}\mathrm{CL} \\
(\mathrm{cm})\end{array}$ \\
\hline Sex & & & & & \\
$\quad$ Females & 44.56 & 10.76 & 39.76 & $5.30 \mathrm{a}$ & 20.01 \\
$\quad$ Males & 44.86 & 11.20 & 39.83 & $4.91 \mathrm{~b}$ & 19.81 \\
Incubator & & & & & \\
Multiple & 44.83 & 11.21 & 39.80 & 4.96 & 19.73 \\
Single & 44.58 & 10.75 & 39.79 & 5.25 & 20.09 \\
Interaction & & & & & \\
Female $\times$ Multiple & 44.71 & 11.04 & 39.76 & 5.17 & $19.90 \mathrm{~b}$ \\
Female $\times$ Single & 44.41 & 10.49 & 39.76 & 5.43 & $20.11 \mathrm{a}$ \\
Male $\times$ Multiple & 44.96 & 11.39 & 39.83 & 4.74 & $19.56 \mathrm{c}$ \\
Male $\times$ Single & 44.76 & 11.00 & 39.82 & 5.07 & $20.06 \mathrm{a}$ \\
P-value & & & & & \\
Sex & & & & & \\
Incubator & 0.152 & 0.172 & 0.731 & 0.030 & $<0.001$ \\
Interaction & 0.822 & 0.121 & 0.960 & 0.101 & $<0.001$ \\
SEM & 0.15 & 0.23 & 0.14 & 0.12 & 0.04 \\
\hline
\end{tabular}

a-c - means with different letters differ $(\mathrm{P}<0.05)$ based on Tukey's honestly significant difference test.

SEM - standard error of the mean; BW - body weight; RYW - relative yolk-sac weight; YFBM - yolk-free body mass; RIW - relative intestine weight; CL - chicken length. four days of incubation, when most of the organs, including the skeletal system, are rapidly maturing. They concluded that high air temperatures and low oxygen concentrations in the machines significantly decreased the length of long bones of chickens (femur and tibia). French (1997) reported that when the eggs are maintained at a constant machine air temperature (MT), as in the MS incubator, the embryo temperature or the EST are below the MT in the first half of the incubation period and above the MT in the other half, which affects embryonic development. Molenaar et al. (2010b) indicated that a constant EST throughout the incubation period can only be achieved by the SS setters because the parameters can be adjusted to compensate for excess embryo heat production. Therefore, if we consider that the main difference between the systems is incubation temperature control, these results agree with those obtained by Lourens et al. (2005) and Molenaar et al. (2010a), who found a lower CL in birds subjected to higher EST $\left(38.9^{\circ} \mathrm{C}\right)$ compared with those incubated under normal EST $\left(37.8^{\circ} \mathrm{C}\right)$.

Regarding BW and yolk-free body mass, no differences were observed between the incubation systems, confirming the results of Oviedo-Rondón et al. (2008), who reported that the BW and yolk sac absorption were not affected by incubation temperatures. By contrast, various experiments indicated that chicks hatched in incubation systems managed with high EST exhibited lower yolk-free body mass at hatching (Leksrisompong et al., 2007; Lourens et al., 2007; Molenaar et al., 2010a; Molenaar et al., 2011; Shim and Pesti, 2011). The differences between these results may be due to other factors in addition to temperature, such as the interaction with batches of eggs with different ages that were incubated inside the machine.

The incubation system did not influence the RIW, confirming the results obtained by Leksrisompong et al. (2007), who observed no differences in this variable when standard EST $\left(38.2^{\circ} \mathrm{C}\right)$ and high EST $\left(40^{\circ} \mathrm{C}\right)$ were used on incubation days 19 and 20. However, in this study, there was an effect of sex on the RIW $(\mathrm{P}<0.03)$, with females showing a higher RIW than males. This result can be explained by the fact that females hatch before males, giving females more time to develop their organs.

We observed an interaction between sex and incubation system for BW and WG $(\mathrm{P}<0.01)$ and FCR at $7 \mathrm{~d}$ of age $(\mathrm{P}<0.06)$. Multiple-stage females were lighter and showed the lowest WG and worst FCR compared with the other treatment (Table 4$)$. This interaction continued during the 8 to $21 \mathrm{~d}$ phase $(\mathrm{P}<0.02$, Table 4$)$ for $\mathrm{BW}$ and $\mathrm{WG}$, with $\mathrm{MS}$ females staying lighter, but the pattern was not maintained for FCR. In the period from 22 to $40 \mathrm{~d}$, there was an effect 


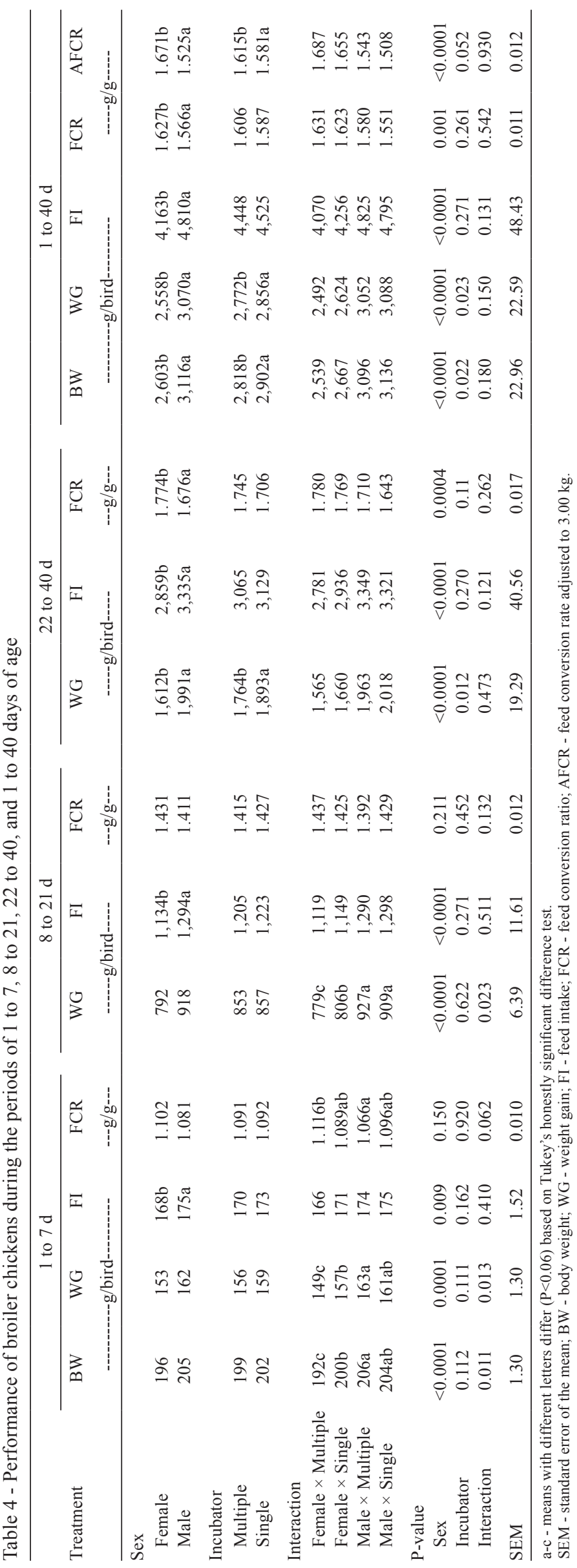

of gender on all variables $(\mathrm{P}<0.01$; Table 4$)$, in which males were heavier, gained more weight, consumed more feed, and were more efficient in converting feed. In the same period, SS chickens gained more weight $(\mathrm{P}<0.01)$ regardless of sex; nevertheless, there were no differences in FI and FCR.

In the total period (1-40 d), no interaction between sex and incubation system was found. The results indicated that the incubation system affected $\mathrm{BW}$ and $\mathrm{WG}(\mathrm{P}<0.02$; Table 5) as well as AFCR ( $<<0.05$; Table 5). Birds hatched in SS were heavier and had higher WG as well as better AFCR compared with those hatched in MS machines for both sexes. The WG was also influenced by gender $(\mathrm{P}<0.01)$, with males gaining more weight than females. Similarly, Silva et al. (2011) indicated that birds hatched in SS setters showed higher daily weight gain and better FCR in relation to those hatched in MS machines. Likewise, data from a study carried out by Oviedo-Rondón et al. (2009a) showed that females hatched in SS systems were heavier at $56 \mathrm{~d}$ of age than females hatched in MS $(\mathrm{P}<0.05)$, with no difference for males. The differences between the incubation systems in relation to $\mathrm{BW}$ and $\mathrm{WG}$ may be due to differences in EST and ventilation rates. The SS system has a different MT for each embryonic incubation phase in order to maintain a constant EST and has different ventilation rates during the incubation process, particularly regulating the $\mathrm{CO}_{2}$ levels . Studies indicate that birds hatched in incubation systems that had higher $\mathrm{CO}_{2}$ levels in the first half of the hatching process, as occurs in SS systems, had better performance at $28 \mathrm{~d}$ of age (De Smit et al., 2006). For FI and FCR (1 to $40 \mathrm{~d})$, no differences due to incubation system were found. The FI was different in all periods for each sex $(\mathrm{P}<0.01)$; females consumed less feed than males, independent of the incubation system.

No differences in the morphology of the duodenum due to incubation system were observed (Table 5). The VH and $\mathrm{CD}$ of duodenum from 0 -d-old chickens (Table 5) indicated a gender effect on $\mathrm{VH}$, in which the females exhibited larger villi relative to males $(\mathrm{P}<0.01)$, without differences in $\mathrm{CD}$. Once again, these results can be explained by the fact that females hatch before males, giving females more time to develop intestinal villi. However, the same did not happen with the development of the jejunal villi, which showed no differences due to sex. In this segment, chickens hatched in the SS system showed higher $\mathrm{CD}(\mathrm{P}<0.04)$ with no differences for $\mathrm{VH}$. The differences in the $\mathrm{VH}$ of the duodenum due to sex that were observed at 0 days of age were not maintained for the first week of life (Table 5). These results are likely due to the significantly higher feed intake by the males. Studies carried out by Potturi et al. 
Table 5 - Intestinal morphology of duodenum and jejunum from chickens of 0 and 7 days of age

\begin{tabular}{|c|c|c|c|c|c|c|c|c|}
\hline \multirow{3}{*}{ Treatment } & \multicolumn{4}{|c|}{0 days } & \multicolumn{4}{|c|}{7 days } \\
\hline & \multicolumn{2}{|c|}{ Duodenum } & \multicolumn{2}{|c|}{ Jejunum } & \multicolumn{2}{|c|}{ Duodenum } & \multicolumn{2}{|c|}{ Jejunum } \\
\hline & $\mathrm{VH}(\mu \mathrm{m})$ & $\mathrm{CD}(\mu \mathrm{m})$ & $\mathrm{VH}(\mu \mathrm{m})$ & $\mathrm{CD}(\mu \mathrm{m})$ & $\mathrm{VH}(\mu \mathrm{m})$ & $\mathrm{CD}(\mu \mathrm{m})$ & $\mathrm{VH}(\mu \mathrm{m})$ & $\mathrm{CD}(\mu \mathrm{m})$ \\
\hline \multicolumn{9}{|l|}{ Sex } \\
\hline Females & $518 \mathrm{a}$ & 56.20 & 381 & 56.53 & 1,339 & 143.77 & 782 & $128.50 \mathrm{a}$ \\
\hline Males & $425 b$ & 53.34 & 407 & 53.94 & 1,343 & 148.20 & 746 & $112.23 b$ \\
\hline \multicolumn{9}{|l|}{ Incubator } \\
\hline \multicolumn{9}{|l|}{ Interaction } \\
\hline Female $\times$ Multiple & 499 & 56.49 & 383 & 54.83 & 1,290 & 135.68 & 778 & 122.47 \\
\hline Female $\times$ Single & 521 & 55.92 & 380 & 58.23 & 1,388 & 151.87 & 785 & 134.53 \\
\hline Male $\times$ Multiple & 408 & 52.04 & 412 & 49.84 & 1,384 & 145.80 & 779 & 111.97 \\
\hline Male $\times$ Single & 442 & 54.63 & 402 & 58.03 & 1,302 & 150.60 & 712 & 112.48 \\
\hline SEM & 19.07 & 1.59 & 15.94 & 1.84 & 34.93 & 5.02 & 34.24 & 5.35 \\
\hline
\end{tabular}

a-b - means with different letters differ $(\mathrm{P}<0.05)$ based on Tukey's honestly significant difference test.

SEM - standard error of the mean; VH - villus height; CD - crypt depth.

(2005) suggest that feed intake is one of the factors that most influence the proliferation of enterocytes and therefore the growth of the villi after hatching. At seven days of age, an influence of gender on the $\mathrm{CD}$ of the jejunum was observed $(\mathrm{P}<0.05$; Table 5$)$, and females had deeper crypts than males. No explanation was found in the literature for these results. In the other variables studied in this period, no effects due to incubation system and sex were observed.

Considering the metabolic responses (Table 6), we can state that during the first week of bird life, the metabolic rate was not influenced by incubation system. However, it was observed that females presented higher metabolization coefficients for gross energy and consequently higher AMEn values $(\mathrm{P}<0.05)$, without differences for coefficients of metabolization of dry matter or crude protein. These results agree with those obtained by Ten Doeschate et al. (1993), who reported that females showed 3\% higher digestibility coefficients compared with males. Similarly, Hughes (2003) reported that the AME of wheat-based diets were influenced by sex, with females exhibiting higher $\operatorname{AME}(3,500$ vs. 3,360 kcal/kg DM). On the other hand, some researchers have reported that sex has no effect on the AMEn (Ravindran et al., 2004) and AME values (Wallis and Balnave, 1984).

The differences between genders found in this experiment may be explained by possible differences in energy costs for repair and maintenance of the gut as well as differences in endogenous losses (Hughes, 2003). Because females hatch before males and the small intestine of birds is immature during the first week of life, in addition to the fact that females showed larger RIW and VH in the duodenum, it is possible that they are in a more advantageous position because there is more space to retain undigested feed and greater absorptive area. However, further research

Table 6 - Coefficients of metabolization of dry matter, crude protein, gross energy, and apparent metabolizable energy corrected for nitrogen of chickens from 5 to 7 days of age

\begin{tabular}{lcccc}
\hline \multirow{2}{*}{ Treatment } & \multicolumn{4}{c}{ Coefficient of metabolization } \\
\cline { 2 - 5 } & $\begin{array}{c}\text { CMDM } \\
\left(\mathrm{g} \mathrm{g}^{-1}\right)\end{array}$ & $\begin{array}{c}\text { CMCP } \\
\left(\mathrm{g} \mathrm{g}^{-1}\right)\end{array}$ & $\begin{array}{c}\text { CMGE } \\
\left(\mathrm{g} \mathrm{g}^{-1}\right)\end{array}$ & $\begin{array}{c}\text { AMEn } \\
\left(\mathrm{kcal} \mathrm{kg}^{-1}\right)\end{array}$ \\
\hline Sex & & & & \\
$\quad$ Female & 0.724 & 0.689 & $0.773 \mathrm{a}$ & $2,960 \mathrm{a}$ \\
$\quad$ Male & 0.712 & 0.673 & $0.758 \mathrm{~b}$ & $2,903 \mathrm{~b}$ \\
Incubator & & & & \\
$\quad$ Multiple & 0.723 & 0.686 & 0.770 & 2,946 \\
$\quad$ Single & 0.712 & 0.676 & 0.604 & 2,914 \\
Interaction & & & & \\
$\quad$ Female $\times$ Multiple & 0.727 & 0.688 & 0.776 & 2,971 \\
Female $\times$ Single & 0.722 & 0.690 & 0.770 & 2,949 \\
$\quad$ Male $\times$ Multiple & 0.720 & 0.684 & 0.765 & 2,925 \\
$\quad$ Male $\times$ Single & 0.702 & 0.661 & 0.751 & 2,878 \\
P-value & & & & \\
$\quad$ Sex & 0.071 & 0.102 & 0.021 & 0.012 \\
Incubator & 0.121 & 0.301 & 0.122 & 0.123 \\
Interaction & 0.391 & 0.230 & 0.51 & 0.561 \\
$\quad$ SEM & 0.38 & 0.52 & 0.34 & 12.09 \\
\hline
\end{tabular}

a-b - means with different letters differ $(\mathrm{P}<0.05)$ based on Tukey's honestly significant difference test.

SEM - standard error of the mean; CMDM - coefficient of metabolization of dry matter; CMCP - coefficient of metabolization of crude protein; CMGE - coefficient of metabolization of gross energy, AMEn - apparent metabolizable energy corrected for nitrogen. 
is needed to evaluate the concentrations of enzymes in the small intestine of females and males to confirm the results obtained in this study.

\section{Conclusions}

The incubation conditions employed in the single-stage incubation system improve the chicken length and crypt depth of jejunum at hatching, resulting in an improvement in broiler performance $(2.98 \%)$, especially in females $(5.04 \%)$. However, unlike the incubation system, sex affects nutrient metabolization coefficients in the first week of the life of the bird.

\section{Acknowledgments}

The authors are grateful to Petersime NV (Zulte, Belgium) for partial funding as well as to Brasil Foods S/A (PR, Brazil) for providing the fertile eggs and the facility to carry out the experiment.

\section{References}

AOAC - Association of Official Analytical Chemists. 1996. Official methods of analysis. 16th ed. Association of Official Analytical Chemists, Washington, DC.

Barri, A.; Honaker, C. F.; Sottosanti, J. R.; Hulet, R. M. and McElroy, A. P. 2011. Effects of incubation temperature on nutrient transporters and small intestine morphology of broiler chickens. Poultry Science 90:118-125.

Bruzual, J. J.; Peak, S. D.; Brake, J. and Peebles, E. D. 2000. Effects of relative humidity during incubation on hatchability and body weight of broiler chicks from young breeder flocks. Poultry Science 79:827-830.

Cortés, M. E. M.; Ribeiro, A. M. L.; Gianfelici, M. F.; Kessler, A. M. and Moraes, M. L. 2009. Study of methodological variations in apparent nutrient metabolism determination in broilers chickens. Revista Brasileira de Zootecnia 38:1921-1927.

De Smit, L.; Bruggeman, V.; Tona, J. K.; Debonne, M.; Onagbesan, O.; Arckens, L.; De Baerdemaeker, J. and Decuypere, E. 2006. Embryonic developmental plasticity of the chick: increased $\mathrm{CO} 2$ during early stages of incubation changes the developmental trajectories during prenatal and postnatal growth. Comparative Biochemistry and Physiology, Part. A 145:166-175.

French, N. A. 1997. Modelling incubation temperature: the effects of incubator design, embryonic development, and egg size. Poultry Science 76:124-133.

Hughes, R. J. 2003. Energy metabolism of chickens: physiological limitations. A report for the Rural Industries Research \& Development Corporation. RIRDC Publication, Barton, Australia.

Hulet, R. M. 2007. Managing incubation: where are we and why? Poultry Science 86:1017-1019.

Hulet, R.; Gladys, G.; Hill, D.; Meijerhof, R. and El-Shiekh, T. 2007. Influence of egg shell embryonic incubation temperature and broiler breeder flock age on posthatch growth performance and carcass characteristics. Poultry Science 86:408-412.

Leksrisompong, N.; Romero-Sanchez, H.; Plumstead, P. W.; Brannan, K. E. and Brake, J. 2007. Broiler incubation. 1. Effect of elevated temperature during late incubation on body weight and organs of chicks. Poultry Science 86:2685-2691.

Lourens, A.; van den Brand, H.; Heetkamp, M. J. W.; Meijerhof, R. and Kempt, B. 2007. Effects of eggshell temperature and oxygen concentration on embryo growth and metabolism during incubation. Poultry Science 86:2194-2199.

Lourens, A.; van den Brand, H.; Meijerhof, R. and Kempt, B. 2005. Effect of eggshell temperature during incubation on embryo development, hatchability, and posthatch development. Poultry Science 84:914-920.

Luna, L. G. 1968. Manual of histologic staining methods of the Armed Forces Institute of Pathology. 3rd ed. McGraw-Hill, New York. p.258.

Molenaar, R.; Meijerhof, R.; van den Anker, I.; Heetkamp, M. J. W.; van den Borne, J. J. G. C.; Kemp, B. and van den Brand, H. $2010 \mathrm{a}$. Effect of eggshell temperature and oxygen concentration on survival rate and nutrient utilization in chicken embryos. Poultry Science 89:2010-2021.

Molenaar, R.; Reijrink, I. A. M.; Meijerhof, R. and van den Brand, H. 2010b. Meeting embryonic requirements of broilers throughout incubation: a review. Brazilian Journal of Poultry Science 12:137-148.

Molenaar, R.; van den Anker, I.; Meijerhof, R.; Kemp, B. and van den Brand, H. 2011. Effect of eggshell temperature and oxygen concentration during incubation on the developmental and physiological status of broiler hatchlings in the perinatal period. Poultry Science 90:1257-1266.

NRC - National Research Council. 1994. Nutrient requirements of poultry. 9th ed. National Academy Press, Washington, D.C.

Oviedo-Rondón, E. O.; Small, J.; Wineland, M. J.; Christensen, V. L.; Grimes, J. L.; Funderburk, S. V. L.; Ort, D. T. and Mann, K. M. 2008. Effects of incubator temperature and oxygen concentration during the plateau stage of oxygen consumption on turkey embryo long bone development. Poultry Science 87:1484-1492.

Oviedo-Rondón, E. O.; Wineland, M. J.; Funderburk, S.; Small, J.; Cutchin, H. and Mann, M. 2009a. Incubation conditions affect leg health in large, high-yield broilers. Journal of Applied Poultry Research 18:640-646.

Oviedo-Rondón, E. O.; Wineland, M. J.; Small, J.; Cutchin, H.; McElroy, A.; Barri, A. and Martin, S. 2009b. Effect of incubation temperatures and chick transportation conditions on bone development and leg health. Journal of Applied Poultry Research 18:671-678.

Peebles, E. D.; Burnham, M. R.; Gardner, C. W.; Brake, J.; Bruzual, J. J. and Gerard, P. D. 2001. Effects of incubational humidity and hen age on embryo composition in broiler hatching eggs from young breeders. Poultry Science 80:1299-1304.

Potturi, P. V. L.; Patterson, J. A. and Applegate, T. J. 2005. Effects of delayed placement on intestinal characteristics in turkey poults. Poultry Science 84:816-824.

Ravindran, V.; Wu, Y. B. and Hendriks, W. H. 2004. Effects of sex and dietary phosphorus level on the apparent metabolizable energy and nutrient digestibility in broiler chickens. Archives of Animal Nutrition 58:405-411.

Ribeiro, A. M. L.; Penz Jr., A. M.; Belay, T. K. and Teeter, R. G. 2001. Comparison of different drying techniques for nitrogen analysis of poultry excreta, feces, and tissue. Journal of Applied Poultry Research 10:21-23.

Shim, M. Y. and Pesti, G. M. 2011. Effects of incubation temperature on the bone development of broilers. Poultry Science 90:1867-1877

Silva, H. S. V.; Lopes, E. F.; Fonseca, B. B.; da Silva, P. L. and Calil, T. A. C. 2011. Desempenho zootécnico de frangos de corte nascidos em sistemas de incubação de estágio único e estágio múltiplo. p.15. In: Lamas Award - FACTA Conference. Fundação APINCO de Ciência e Tecnologia Avícola, São Paulo, Brazil. 
Ten Doeschate, R. A.; Scheele, C. W.; Schreurs, V. V. and van der Klis, J. D. 1993. Digestibility studies in broiler chickens: influence of genotype, age, sex and method of determination. British Poultry Science 34:131-146.

Uni, Z.; Tako, E.; Gal-Garber, O. and Sklan, D. 2003. Morphological, molecular and functional changes in the chicken small intestine of the late-term embryo. Poultry Science 82:1747-1754.

Wallis, I. R. and Balnave, D. 1984. The influence of environmental temperature, age and sex on the digestibility of amino acids in growing broiler chickens. British Poultry Science 25:401-407.
Willemsen, H.; Kamers, B.; Dahlke, F.; Han, H.; Song, Z.; Ansari Pirsaraei, Z.; Tona, K.; Decuypere, E. and Everaert, N. 2010. High and low temperature manipulation during late incubation: Effects on embryonic development, the hatching process, and metabolism in broilers. Poultry Science 89:2678-2690.

Wineland, M. W.; Christensen, V. L.; Yildrum, I.; Fairchild, B. D.; Mann, K. M. and Ort, D. T. 2006. Incubator temperature and oxygen concentration at the plateau stage in oxygen consumption affects intestinal maturation of broiler chicks. Poultry Science 89:2678-2690. 